\title{
Effects of Microstructural Heterogeneity on Very-High-Cycle Fatigue Properties of 7050-T7451 Aluminum Alloy Friction Stir Butt Welds
}

Caiyan Deng, Hong Wang, Baoming Gong*, Xiang Li and Zhenyu Lei

1. Department of Materials Science and Engineering, Tianjin University, Tianjin 300072, China.

2. Tianjin Key Laboratory of Advanced Joining Technology, Tianjin 300072, China.

*Corresponding Author Email: gongbm@tju.edu.cn

\begin{abstract}
$^{1}$
In this study, the very-high-cycle fatigue properties of 7050 aluminum alloy and its friction stir welding (FSW) butt welds have been investigated. The results show that the failure of FSW joints still occurs at $7.0 \times 10^{8}$ cycles. The fatigue properties of the FSW joint are superior to those of the base material, especially in the super long life regime. Most fatigue cracks initiate at the thermo-mechanically affected zone and heat affected zone on the advancing side of the FSW joints, and the susceptibility of these zones to fatigue is attributed to the metallurgical heterogeneity.
\end{abstract}

Keywords: friction stir welding; aluminum alloy; welded joint; fatigue; electron backscatter diffraction

${ }^{1}$ Friction Stir Welding (FSW), High-Cycle-Fatigue (HCF), Very-High-Cycle Fatigue (VHCF), Heat Affected Zone (HAZ), Thermo-Mechanically Affected Zone (TMAZ), Metal Inert Gas Welding (MIG), Tungsten Inert Gas Welding (TIG), Scanning Electron Microscopy (SEM), Electron Backscatter Diffraction (EBSD), Energy Dispersive Spectrometry (EDS), Nondestructive Testing (NDT) 


\section{Introduction}

Friction stir welding (FSW) is a typical solid-state joining technology that was invented by The Welding Institute (TWI) in 1991 [1]. FSW uses a rotating and traversing nonconsumable tool to generate frictional heat that causes mechanical deformation at the joint. The technology easily provides defect-free welds in materials with poor fusion-weldability. For instance, conventional fusion welding methods for aluminum alloys often produce some porosity in the weld metal [2,3], which deteriorates the mechanical properties, especially the fatigue properties. Therefore, FSW is widely used for the 2XXX-and 7XXX-series aluminum alloys that are known as difficult-to-weld metals [4]. Extensive studies on FSW of aluminum alloys have been performed by many researchers [5-7]. Owing to the fine recrystallization in the stir zone and the absence of the geometrical notch effect and misalignment in fusion-welded joints, it is expected that aluminum friction stir welds may have superior fracture and fatigue behavior to their fusion counterparts, and the structural reliability of FSW components can be substantially improved [8]. Lomolino et al. [9] recently suggested fatigue-life design curves for friction stir welded joints, where the fatigue strength at $2 \times 10^{6}$ cycles was used to identify the fatigue class as recommended by IIW [10]. However, extensive experiments have demonstrated that structural materials such as ferrous alloys, titanium alloys, and aluminum alloys exhibited no fatigue limit at $10^{7}$ cycles or higher, and the $\mathrm{S}-\mathrm{N}$ curve exhibited a continuous downward shape in the high-cycle fatigue (HCF) regime. As a result, fatigue failure still occurred when the cycles was extended into the very-high-cycle fatigue (VHCF) regime [11-14]. Therefore, fatigue reliability and damage tolerance of FSW in the VHCF regime is a major concern in determining the in-service life of the FSW structural components in aerospace and aeronautical engineering.

Because the rotating FSW tool induces localized heating and plastic flow of the welded material which is followed by the rapid cooling, the heterogeneity of the microstructure in FSW is thus inevitable. Accordingly, the microstructure of the FSW joint is generally divided into three zones: the heat affected zone 
(HAZ), the thermo-mechanically affected zone (TMAZ), and the stir zone. The latter is characterized by an equiaxial dynamically recrystallized microstructure with strength comparable to the base material. The HAZ and TMAZ are the narrow bands between the base material and the stir zone with a relatively lower strength.

The microstructural heterogeneity gives rise to the complexity in mechanical properties of FSW joints, especially fatigue behaviors. Therefore, the fatigue properties of the FSW joint have been investigated by many researchers $[8,15,16]$. Dai et al. [15] found the highest fatigue crack propagation rate in the stir zone, which seems to violate the intuition that the fine equiaxed grains caused by recrystallization were a benefit to the fatigue performance. Ericsson and Sandström [3] reported that metal inert gas (MIG)-pulse and tungsten inert gas (TIG) welds exhibited lower static and dynamic strengths than friction stir welds. Sutton et al. [17] investigated the influence of the microstructure of FSW joints of 2024-T3 on the fracture behavior. In addition to the microstructure, the tool marks and burrs may be formed on the top surface; a lack of bonding in the weld root may appear due to the short pin. Moreover, fatigue cracks are likely to originate from such surface asperities or root flaws, resulting in inferior fatigue performance as reported in the literature [18-20].

In the study, the VHCF fatigue behavior of FSW joints of 7050-T7451 aluminum alloy is investigated and compared to that of the base material. The primary objective of the present work is to explore the relationship between the microstructural heterogeneity and the defect and VHCF properties of the FSW joints.

\section{Fatigue test}

The test material is a 7050-T7451 aluminum alloy rolled plate. The nominal chemical composition and mechanical properties of this material are listed in Table 1. The surface layer of the plates was ground just before the FSW process to remove the oxide layer. All of the welds were produced with the same FSW machine, and the weld axis was always parallel to the parent plate rolling direction as shown in Fig. 1. The 
welding parameters are listed in Table 2. No post-weld heat treatment was carried out for the joints. Fatigue test specimens with a dog-bone shape with a constant cross section in the middle gauge were extracted from the welded plates with dimensions of $250 \mathrm{~mm} \times 300 \mathrm{~mm} \times 12 \mathrm{~mm}$ (see Fig. 2). The dimensions of the specimens were determined using an analytical method to ensure that the stir zone, TMAZ and the HAZ adjacent to TMAZ resonate longitudinally at approximately $20 \mathrm{kHz}$ under the same stress levels [21]. All specimens were ground and polished to a smooth finish before the fatigue tests. Fatigue testing was carried out using a piezoelectric ultrasonic fatigue machine in push-pull mode. The specimens were tested in air at room temperature with the stress ratio $R=-1$. The fatigue stress was actually derived from the displacement amplitude of the vibrating specimen. A water-cooling system was used to maintain the specimen temperature at the ambient temperature.

[Table 1, Table 2, Figure 1 and Figure 2 about here]

Scanning electron microscopy (SEM) was used for fractographical observation. The chemical compositions of the inclusions were determined by energy dispersive spectrometry (EDS). An electron backscatter diffraction (EBSD) analysis was performed using a JSM-7001F thermal field-emission scanning electron microscope with an acceleration voltage of $20 \mathrm{kV}$. Images were collected and processed by the TSL software to obtain the grain distribution and grain-boundary orientation maps of different locations on the joints.

\section{Experimental results}

Figure 3 shows the S-N curves of the base material and the FSW butt joints, ranging from $2 \times 10^{6}$ to $1 \times 10^{9}$ cycles. The experimental results indicate that there exists no fatigue limit in both fatigue curves. The curves still exhibit a continuously decreasing trend beyond $10^{7}$ cycles. At $10^{7}$ cycles, the fatigue strength of the 7050 aluminum alloy is approximately $230 \mathrm{MPa}$, consistent with the experimental results in the literature 
[22]. In addition, there exists a short life specimen in the tests of the welded joint. The fatigue life $\left(5.24 \times 10^{5}\right.$ cycles) of this specimen decreases dramatically, which is only $0.129 \%$ of the other specimens $\left(4.05 \times 10^{8}\right.$ cycles) at the same low stress level (138 MPa). Figure 4a shows the fatigue specimen fracture surface with an incomplete penetration defect. Vickers hardness tests (HV10) were performed at the mid-thickness of the specimen, and the results are presented in Fig. 5.

Accordingly, it is found experimentally that the fatigue strength of the FSW joint is not only higher than that of the base material, especially in the super long life region, but the scatter band of the welded joint specimens is much narrower, which may indicate different failure mechanisms between the two. In the following discussion, we focus on the comparison of the VHCF behaviors of the FSW joint and the base material in terms of the crack initiation sites, microstructural heterogeneity, and defect effects.

[Figures 3, 4 and 5 about here]

\section{Discussion}

\subsection{Preferred fatigue crack initiation site}

Figure 2 illustrated schematically the distributions of the stress amplitude for a cylindrical specimen with a constant cross section in the gauge. The distribution of the stress amplitude along the experimental gauge length is almost at the same level. Statistical results for the locations of fracture of two types of specimens are reported in Fig. 6. It is found that the failure positions of the base metal specimens are randomly distributed along the gauge; in contrast, only a few of specimens fracture in the stir zone of the FSW joints, and most of failure appears in the TMAZ or HAZ on the advancing side. The same phenomenon was also reported for an Al-Mg-Sc alloy in which fatigue cracks were likely to initiate on the advancing side of the stir zone [23]. Considering the mechanical and microstructural difference among the stir zone, TMAZ and HAZ, it is supposed that the phenomena are closely related to the microstructural heterogeneity and 
defects in FSW joint. More specifically, the preferred crack initiation site is significantly affected by the welding defects, grain orientation, load direction, etc.

[Figure 6 about here]

\subsection{Microstructural heterogeneity}

Owing to the asymmetric flow of plasticized materials, these regions with distinct microstructures are shown in Fig. 7a. It can be observed in Fig. $7 \mathrm{~b}$ that the stir zone is composed of equiaxed grains caused by dynamic recrystallization, and the homogeneous fine grains with a size of 1 to $10 \mu \mathrm{m}$ are formed in this zone.

Figures $7 \mathrm{c}$ and $7 \mathrm{~d}$ show the grain distribution and orientation in the TMAZs of the advancing side and the retreating side, respectively. Under the effect of an insufficient thermal cycle, the grains are severely distorted and elongated at a certain angle inclined toward the original extrusion orientation of the base material. The bending of the grains in the TMAZ region suggests that the stirring action of the friction stir process causes the flat grains of the parent material to be drawn into the stir zone as shown in Fig. 7a. As a result, the grains in the TMAZ are coarsened and partly recrystallized compared to the stir zone. The difference between the microstructures on the advancing and retreating sides can be told in Figs. $7 \mathrm{c}$ and $7 \mathrm{~d}$. Compared with the retreating side, the distinction between the stir zone and the TMAZ can be more easily identified on the advancing side.

The grain boundary misorientation distribution of the FSW joint is investigated using the EBSD. Figures $8 \mathrm{a}-\mathrm{c}$ show the typical bimodal shape of the grains in the stir zone and TMAZ, where the peaks are located below $10^{\circ}$ and at approximately $45^{\circ}$, and most of the boundaries have a high angle misorientation with greater than $15^{\circ}$. In contrast, the grain misorientation less than $15^{\circ}$ at the positions of the $\mathrm{HAZ}$ takes up to $69.6 \%$ (see Fig. 8d). Accordingly, it is speculated that the dynamic recrystallization process accompanying plastic flow results in an increase in the density of grain boundaries. Furthermore, it is considered that a high 
misorientation can act as an energy barrier that hinders crack initiation and kink propagation of a crack. Jian et al. [24] analyzed the fatigue crack growth of 2124 aluminum alloy using EBSD technology and discovered that the crack propagation path changes owing to the misorientation between adjoining grains. As discussed previously, the experimental results indicate that VHCF failure of the FSW specimens primarily originates on the advancing side, which was also observed by Zhou et al. [25]. The misorientation angle distribution in Fig. $8 \mathrm{~b}$ reveals more low-angle boundaries on the advancing side. Although the grain morphology and size in the vicinity of the HAZ and the TMAZ on the retreating side are similar to those on the advancing side, the different plastic flow of the weld and the base metals on the two sides leads to different thermal cycle effects. The temperature on the retreating side is higher than that on the advancing side [26], and recrystallization proceeds more sufficiently and results in much more high-angle grain boundaries. The analysis is also consistent with the hardness profile in Fig. 5. Since the alloy is mainly strengthened by solid-solution and work hardening, the local softening of the FSW joint is usually attributed to the strengthening precipitates dissolving. It is found in Fig. 5 that a significant decrease in the hardness is observed on the advancing and retreating sides in the HAZ, equal to $65 \%$ of the parent metal hardness. Regarding to the HAZ hardness, no significant difference from the base material could be observed due to a limited influence of the welding thermal cycle. Furthermore, owing to grain-boundary migration resistance and a lack of recrystallization dynamics, the growth of grains in the HAZ is severely constrained by the initial grain size, and the strengthening precipitates may further coarsen [27]. As a result, the minimum hardness is found in the HAZ on the advancing, which tends to be a relatively weak link.

Considering the metallurgical heterogeneity during the FSW process, it is concluded that there may exist 'notch effects' on the advancing side of the FSW joint which leads to inferior crack initiation threshold in the gigacycle fatigue; the local softening is also able to characterize by the Vickers hardness profile and the misorientation distribution comprised of low-angle boundaries. It is usually assumed that the former is in 
favor of crack initiation, and the latter can reduce the crack propagation resistance significantly.

[Figure 8 about here]

\subsection{Fractographic observation}

The crack sources in the specimens can be divided into two different types, namely, surface and internal ones. Subsurface inclusions and incomplete penetration are usually identified as the latter. It is found in Fig. 9 that the fracture surface of the base metal is relatively flat with a crack initiating at the surface. As regards the FSW joint observed in Fig. 10, the crack also originates from the surface of the specimen, even though a noticeable welding defect exists in the interior of the section.

Based on the extensive experimental observation, Hong et al. considered that there was a competition between surface crack initiation and interior crack initiation in the VHCF [28]. It is concluded that the fatigue life increases as the size of inclusion decreases or the distance from the inclusion to the surface increases [29]. Therefore, considering the location of the internal inclusion, surface or sub-surface defect dominates the crack initiation for the case.

[Figures 9 and 10 about here]

\subsection{Defect effects}

Although the FSW joint is exempt from the defects associated with fusion welding, there still exist some unique defects such as burrs and flash, grooves, streaks, cavities, zigzag lines, and incomplete penetration. In the section, the effects of inclusions and incomplete penetration for gigacycle fatigue are analyzed.

\subsubsection{Inclusions}

Through an EDS analysis, the inclusions in Fig. 11 are identified as $\mathrm{Al}_{2} \mathrm{O}_{3}$. Owing to an inappropriate pretreatment, either the oxide layer or the non-removed dust and oil remnant on the surface of the aluminum alloy was not entirely broken and subsequently dispersed into the stir zone. Depending on size and location, 
the dispersive distribution of $\mathrm{Al}_{2} \mathrm{O}_{3}$ may affect the fatigue life of the FSW joint. It can be seen from the fractographic observation that some of the fractures are initiated from these subsurface inclusions, but only few occur at interior inclusions. Specifically, the inclusions closer to the surface with a larger size are likely to become crack sources and result in inferior fatigue properties. It is observed in this study that the inclusions introduced by FSW process are mainly distributed at the interior of the butt surface (as marked in Fig. 10a). As discussed previously, the effect of the internal inclusions of the welded joints is expected to be negligible.

[Figure 11 about here]

\subsubsection{Incomplete penetration}

Incomplete penetration defects might not be detected with normal nondestructive testing (NDT) methods. The incomplete penetration interface is the original butt surface of the plate that remains to be jointed. Inaccessibility of the tool pin to the bottom of welds causes a deficient heat input, leading to incomplete dynamic recrystallization. Incomplete penetration defects always take the form of a root flaw

(Fig. 4b). Root flaw should be assumed to be crack-like from the outset of any fatigue loading [10, 19]. A high stress concentration appears at the vertex of planar defects, which leads to a significant decrease in the fatigue life. The relationship between the crack-like flaws of different lengths and the tensile strengths of the 2219-T6 aluminum alloy FSW butt joints was investigated in [30], revealing that longer or deeper root flaws favored crack initiation and accelerate the crack propagation rate. Dickerson and Przydatek [19] showed that root flaws up to a certain length can affect the failure performance of the FSW joints significantly. Besel et al. [23] reported that incomplete welding acted as a potential fatigue crack origin and brought about a lower fatigue life.

Table 3 summarizes the fatigue strength of the base metal and the welded joint specimens for $10^{7}, 10^{8}$, and $10^{9}$ cycles. It is found that there is little difference in the fatigue strengths between the welded joint and 
the base metal specimens if the welding defects are properly controlled. Moreover, the fatigue properties of the FSW specimen are superior to those of the MIG specimen as reported by [8]. Therefore, the control of the quality of the FSW (especially for incomplete penetration defects) combined with the appropriate NDT are vital to prolong the service life of the FSW structures.

[Table 3 about here]

\section{Summary}

In the study, the VHCF properties of a 7050 aluminum alloy and its butt welds under ultrasonic fatigue tests are investigated in terms of the microstructural heterogeneity and defects, and the following conclusions can be drawn:

(1) For both the base metal and the FSW joint specimens, fatigue failure still occurs beyond $10^{7}$ cycles and even at $10^{9}$ cycles. The fatigue endurance stress continuously decreases as the number of cycles to failure increases, and no traditional fatigue limit could be determined;

(2) The fracture positions of the base metal specimens are randomly distributed in the parallel part, whereas fatigue failure mainly occurs in the TMAZ and HAZ on the advancing side of the FSW joints. This phenomenon is attributed to the microstructural heterogeneity of the FSW joint. Based on the EBSD analysis and hardness distribution, it is assumed that there exist the weakest link on the advancing side of the FSW joint which leads to inferior crack initiation threshold in the gigacycle fatigue;

(3) Through the fractographic analyses, it is considered that there is a competitive mechanism between the size and location of the inclusions for the VHCF crack initiation in the FSW joints: both the decrease in the distance between the inclusion and the surface and the increase in the inclusion size result in the crack initiation dominated by surface or sub-surface defect, and vice versa. It is observed experimentally that incomplete penetration in FSW joint is equivalent to the crack-like defect, and crack initiation phase of the fatigue life can be negligible. 


\section{Acknowledgements}

The research is financially supported by the National Science Foundation of China (Grant No. 51375331).

\section{References}

[1] W.M. Thomas, E.D. Nicholas, J.C. Needham, M.G. Murch, P. Templesmith, C.J. Dawes, G.B Patent Application No. 9125978.8 (December 1991).

[2] R.S. Mishra, Z.Y. Ma. Friction stir welding and processing. Mater Sci Eng R 50 (2005) 1-78.

[3] M. Ericsson, R. Sandström. Influence of welding speed on the fatigue of friction stir welds, and comparison with MIG and TIG. Int J Fatigue 25 (2003) 1379-1387.

[4] A Heinz, A Haszler, C Keidel, S Moldenhauer, R Benedictus, W.S Miller. Recent development in aluminum alloys for aerospace applications. Mater Sci Eng A Struct 280 (2000) 102-107.

[5] H.J. Liu, Y.C. Chen, J.C. Feng. Effect of zigzag line on the mechanical properties of friction stir welded joints of an Al-Cu alloy. Scripta Mater 55 (2006) 231-234.

[6] H.K. Rafi, G.D. Janaki Ram, G. Phanikumar, K.P. Rao. Microstructure and tensile properties of friction welded aluminum alloy AA7075-T6. Mater Des 31 (2010) 2375-2380.

[7] F. Zhang, X.K. Su, Z.Y. Chen, Z.R. Nie. Effect of welding parameters on microstructure and mechanical properties of friction stir welded joints of a super high strength Al-Zn-Mg-Cu aluminum alloy. Mater Des 67 (2015) 483-491.

[8] P.M.G.P. Moreira, M.A.V. de Figueiredo, P.M.S.T. de Castro. Fatigue behaviour of FSW and MIG weldments for two aluminium alloys. Theor Appl Fract Mech 48 (2007) 169-177.

[9] S. Lomolino, R. Tovo, J. dos Santos. On the fatigue behaviour and design curves of friction stir butt-welded Al alloys. Int J Fatigue 27 (2005) 305-316. 
[10] A. Hobbacher. Fatigue design of welded joints and components, International Institute of Welding (IIW)/Abington Publishing, Cambridge, 2002.

[11] Q.Y. Wang, T. Lib, X.G. Zenga. Gigacycle fatigue behavior of high strength aluminum alloys. Procedia Eng 2 (2010) 65-70.

[12] J. Bach, H.W. Höppel, M. Prell, M. Göken. Crack initiation mechanism in AA6082 fatigued in the VHCF-regime. Int J Fatigue 60 (2014) 23-27.

[13] M. Meischel, S.E. Stanzl-Tschegg, A. Arcari, N. Iyyer, N. Apetre, N.Phan. Constant and variable-amplitude loading of aluminum alloy 7075 in the VHCF regime. Procedia Eng 101 (2015) $501-508$.

[14] X.L. Liu, C.Q. Sun, Y.S. Hong. Effects of stress ratio on high-cycle and very-high-cycle fatigue behavior of a Ti-6Al-4V alloy. Mater Sci Eng A 622 (2015) 228-235.

[15] Q.L. Dai, Z.F. Liang, G.Q. Chen, L.C. Meng, Q.Y. Shi. Explore the mechanism of high fatigue crack propagation rate in fine microstructure of friction stir welded aluminum alloy. Mater Sci Eng A 580 (2013) 184-190.

[16] G. D’Urso, C. Giardini, S. Lorenzi, T. Pastore. Fatigue crack growth in the welding nugget of FSW joints of a 6060 aluminum alloy. J Mater Process Technol 214 (2014) 2075-2084.

[17] M.A. Sutton, B. Yang, A.P. Reynolds, R. Taylor. Microstructural studies of friction stir welds in 2024-T3 aluminum. Mater Sci Eng A 323 (2002) 160-166.

[18] S.S. Di, X.Q. Yang, G.H. Luan, B. Jian. Comparative study on fatigue properties between AA2024-T4 friction stir welds and base materials. Mater Sci Eng A 435-436 (2006) 389-395.

[19] T.L. Dickerson, J. Przydatek. Fatigue of friction stir welds in aluminum alloys that contain root flaws. Int J Fatigue 25 (2003) 1399-1409.

[20] C.Z. Zhou, X.Q. Yang, G.H. Luan. Effect of root flaws on the fatigue property of friction stir welds in 
2024-T3 aluminum alloys. Mater Sci Eng A 418 (2006) 155-160.

[21] T.E. Matikas. Specimen design for fatigue testing at very high frequencies. J Sound Vib 247 (2001) 673-681.

[22] Y.L. Wang, Q.L. Pan, L.L. Wei, B. Li, Y. Wang. Effect of retrogression and reaging treatment on the microstructure and fatigue crack growth behavior of 7050 aluminum alloy thick plate. Mater Des 55 (2014) 857-863.

[23] M. Besel, Y. Besel, U.A. Mercado, T. Kakiuchi, Y. Uematsu. Fatigue behavior of friction stir welded Al-Mg-Sc alloy. Int J Fatigue 77 (2015) 1-11.

[24] H.G. Jian, Z.M. Yin, F. Jiang, X. Li. EBSD analysis of fatigue crack growth of 2124 aluminum alloy for aviation. Rare Met Mater Eng 43 (2014) 1332-1336.

[25] C.Z. Zhou, X.Q. Yang, G.H. Luan. Investigation of the microstructure and fatigue properties of friction stir welded Al-Mg alloy. Mater Chem Phys 98 (2006) 285-290.

[26] R.D. Fu, Z.Q. Sun, R.C. Sun, Y. Li, H.J. Liu, L. Liu. Improvement of weld temperature distribution and mechanical properties of 7050 aluminum alloy butt joints by submerged friction stir welding. Mater Des 32 (2011) 4825-4831.

[27] K.V. Jata, K.K. Sankaran, J.J. Ruschau. Friction-stir welding effects on microstructure and fatigue of aluminum alloy 7050-T7451. Metall Mater Trans A Phys 31A (2000) 2181-2192.

[28] Y.S. Hong, A.G. Zhao, G.A. Qian, C.G. Zhou. Fatigue strength and crack initiation mechanism of very-high-cycle fatigue for low alloy steels. Metall Mater Trans A Phys 43 (2012) 2753-2762.

[29] G.A. Qian, Y.S. Hong, C.G. Zhou. Investigation of high cycle and very-high-cycle fatigue behaviors for a structural steel with smooth and notched specimens. Eng Fail Anal 17 (2010) 1517-1525.

[30] B. Li, Y.F. Shen, W.Y. Hu. The study on defects in aluminum 2219-T6 thick butt friction stir welds with the application of multiple non-destructive testing methods. Mater Des 32 (2011) 2073-2084. 


\section{List of Table Captions}

Table 1: Chemical composition and mechanical properties of 7050 aluminum alloy.

Table 2: Process parameters of FSW 7050-T7451 joints.

Table 3: Fatigue strength of specimens $\left(1 \times 10^{7}, 1 \times 10^{8}\right.$ and $\left.1 \times 10^{9}\right)$. 
Table 1 Chemical composition and mechanical properties of 7050 aluminum alloy.

\begin{tabular}{lccccccccccc}
\hline Alloy & $\rho /{\mathrm{g} . \mathrm{cm}^{-3}}^{-}$ & $\sigma_{s} / \mathrm{MPa}$ & $\sigma_{b} / \mathrm{MPa}$ & $\mathrm{E} / \mathrm{GPa}$ & $\mathrm{Zn}$ & $\mathrm{Mg}$ & $\mathrm{Cu}$ & $\mathrm{Fe}$ & $\mathrm{Si}$ & $\mathrm{Ti}$ & $\mathrm{Zr}$ \\
\hline 7050 & 2.830 & 455 & 510 & 72 & 6.33 & 2.12 & 2.18 & 0.08 & 0.05 & 0.03 & 0.09 \\
\hline
\end{tabular}


Table 2 Process parameters of FSW 7050-T7451 joints.

\begin{tabular}{cccccc}
\hline $\begin{array}{c}\text { Diameter of } \\
\text { shoulder } \\
(\mathrm{mm})\end{array}$ & $\begin{array}{c}\text { Root diameter of } \\
\text { pin(mm) }\end{array}$ & $\begin{array}{c}\text { Top diameter of } \\
\text { pin }(\mathrm{mm})\end{array}$ & $\begin{array}{c}\text { Length of } \\
\text { pin } \\
(\mathrm{mm})\end{array}$ & $\begin{array}{c}\text { Rotation } \\
\text { speed } \\
(\mathrm{rpm})\end{array}$ & $\begin{array}{c}\text { Welding } \\
\text { speed } \\
(\mathrm{mm} / \mathrm{min})\end{array}$ \\
\hline 25 & 12 & 6 & 11 & 300 & 95 \\
\hline
\end{tabular}


Table 3 Fatigue strength of specimens $\left(1 \times 10^{7}, 1 \times 10^{8}\right.$ and $\left.1 \times 10^{9}\right)$.

\begin{tabular}{cccc}
\hline Status & $\Delta \sigma /(\mathrm{MPa})\left(1 \times 10^{7}\right)$ & $\Delta \sigma /(\mathrm{MPa})\left(1 \times 10^{8}\right)$ & $\Delta \sigma /(\mathrm{MPa})\left(1 \times 10^{9}\right)$ \\
\hline Base metal specimen & 230 & 169 & 124 \\
Butt weld specimen & 229 & 170 & 126 \\
Decrease degree $(\%)$ & 0.43 & -0.59 & -1.61 \\
\hline
\end{tabular}




\section{List of Figure Captions}

Figure 1: Schematic of the friction stir welding (FSW) process.

Figure 2: The dimensions and the stress amplitude distribution of the fatigue specimen.

Figure 3: The S-N curves for the base metal and the FSW joint.

Figure 4: Fatigue fracture surface of defective specimen (a) and incomplete penetration (b).

Figure 5: Distribution of Vickers hardness across the FSW joint.

Figure 6: Fracture position of the specimens (a) base metal; (b) FSW joint.

Figure 7: Cross-section of the FSW joint for 7075-T7451 alloy (I: stir zone; II: TMAZ; III: HAZ) (a); microstructures of FSW joint for the stir zone (b); TMAZ at advancing side (c); TMAZ at retreating side (d); HAZ (e).

Figure 8: Grain and misorientation angle distribution of the FSW joint for the stir zone (a); TMAZ at advancing side (b); TMAZ at retreating side (c); HAZ (d).

Figure 9: Fractographic observation of the base metal: (a) low magnification; (b) high magnification at the crack source.

Figure 10: Fractographic observation of the FSW welded joints.

Figure 11: EDS analysis for the inclusion (a); the FSW joint substrate (b). 


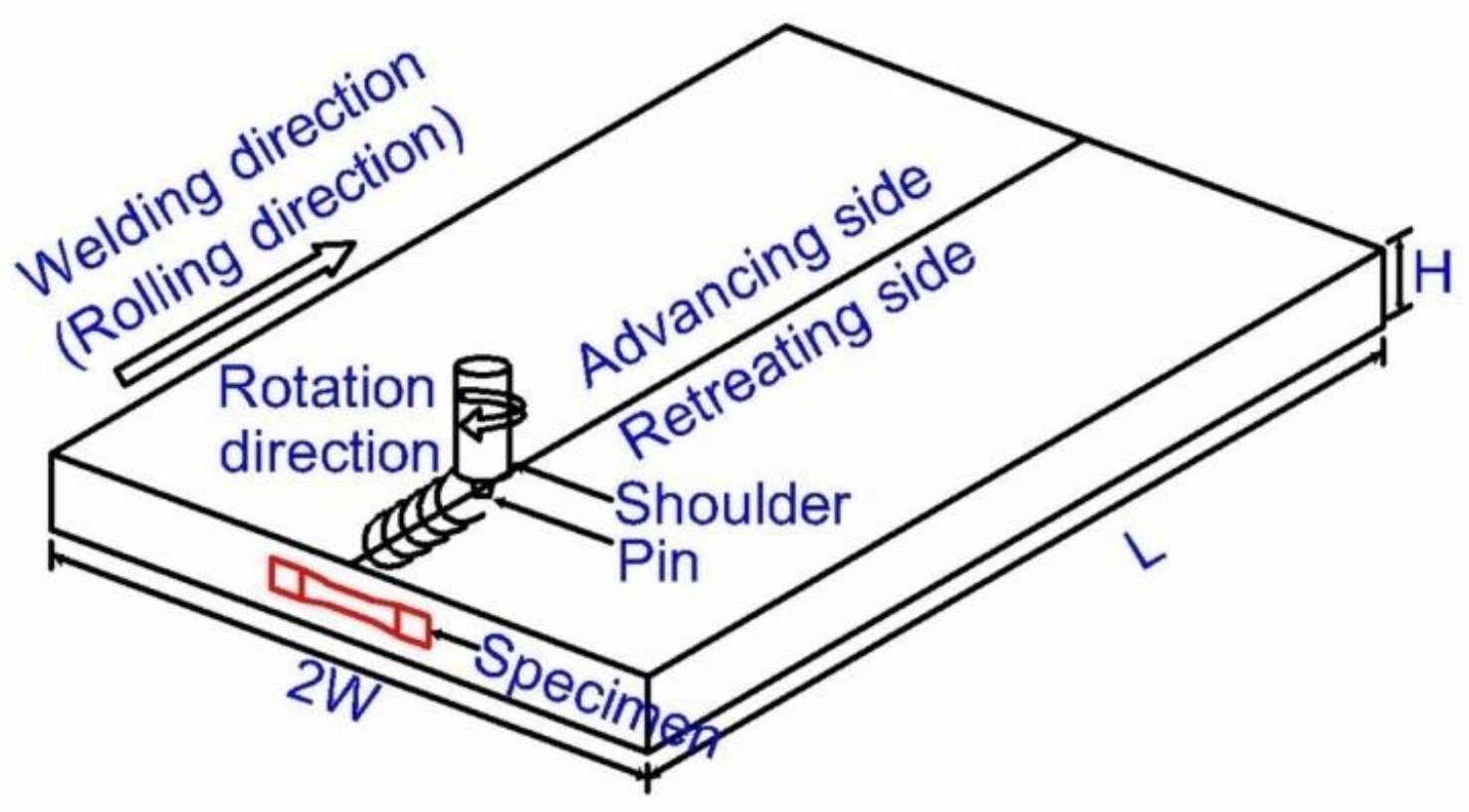

Fig. 1 Schematic of the friction stir welding (FSW) process. 

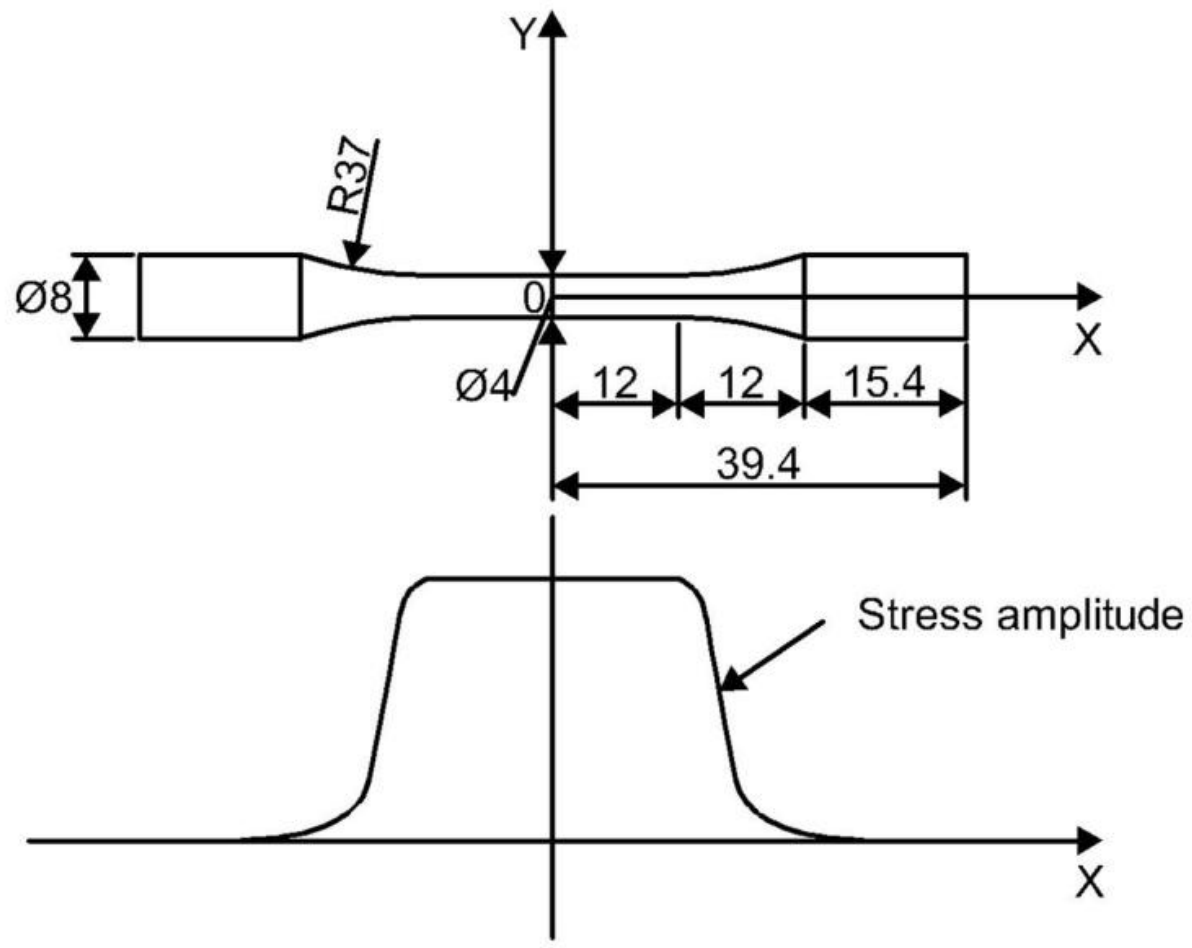

Fig. 2 The dimensions and the stress amplitude distribution of the fatigue specimen. 


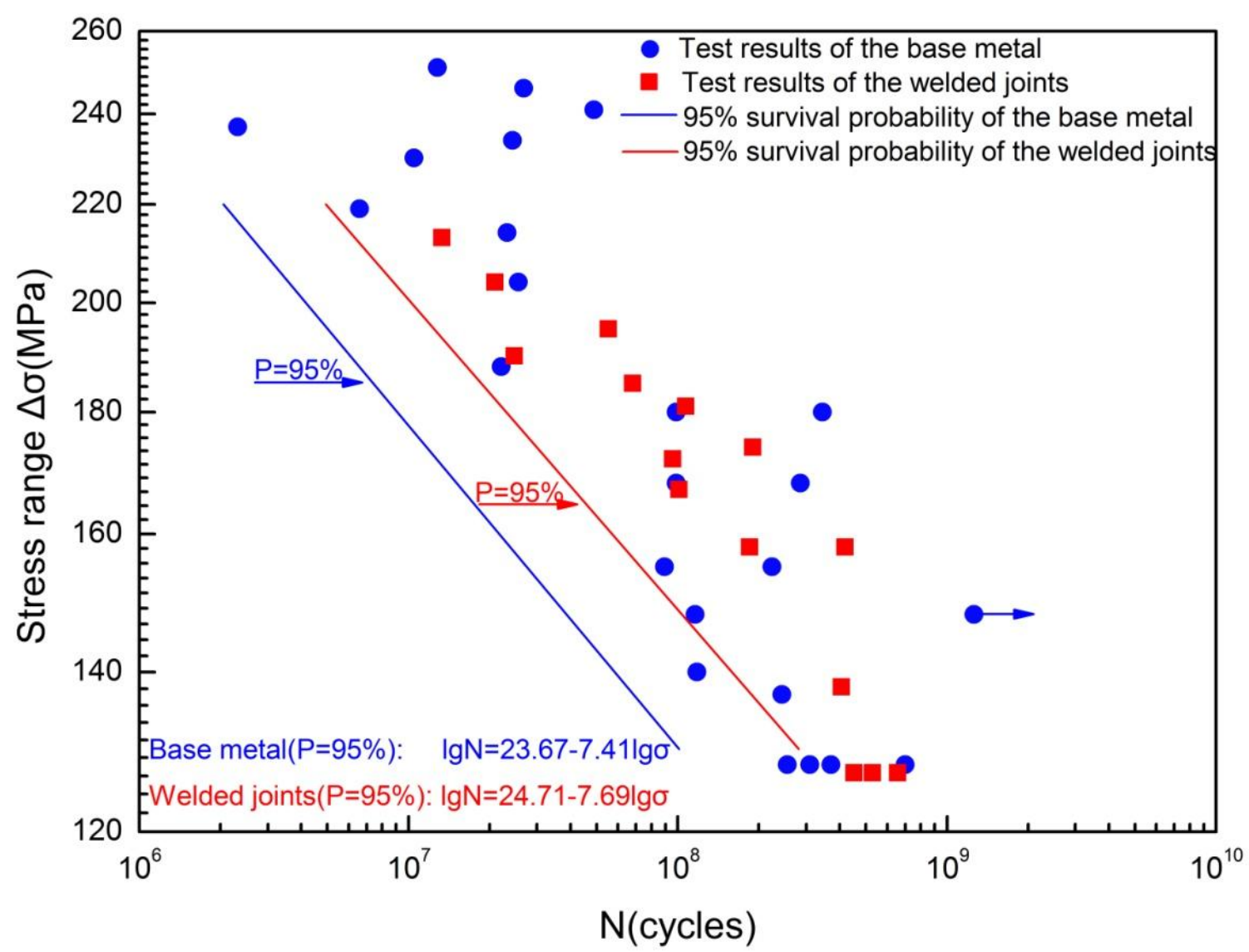

Fig. 3 The S-N curves for the base metal and the FSW joint. 


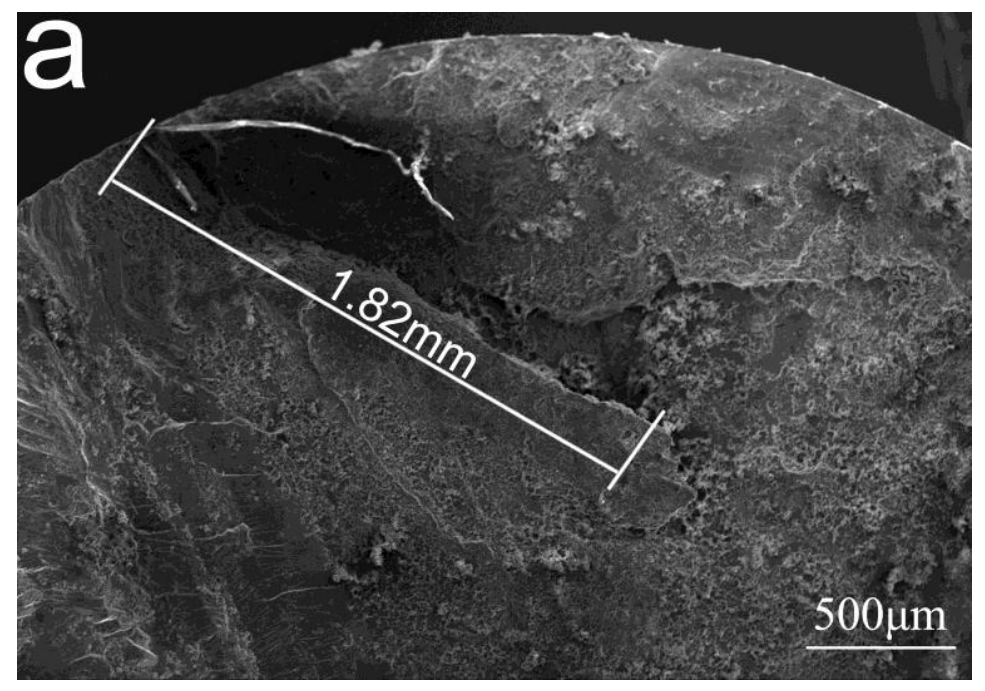

(a)

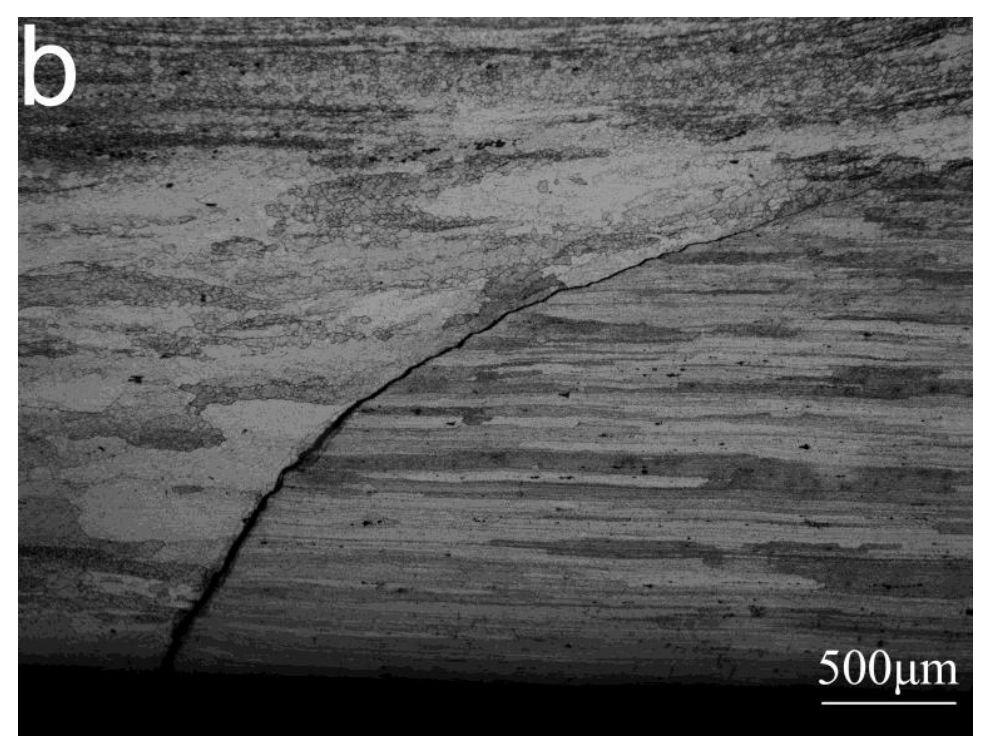

(b)

Fig. 4 Fatigue fracture surface of defective specimen (a) and incomplete penetration (b). 


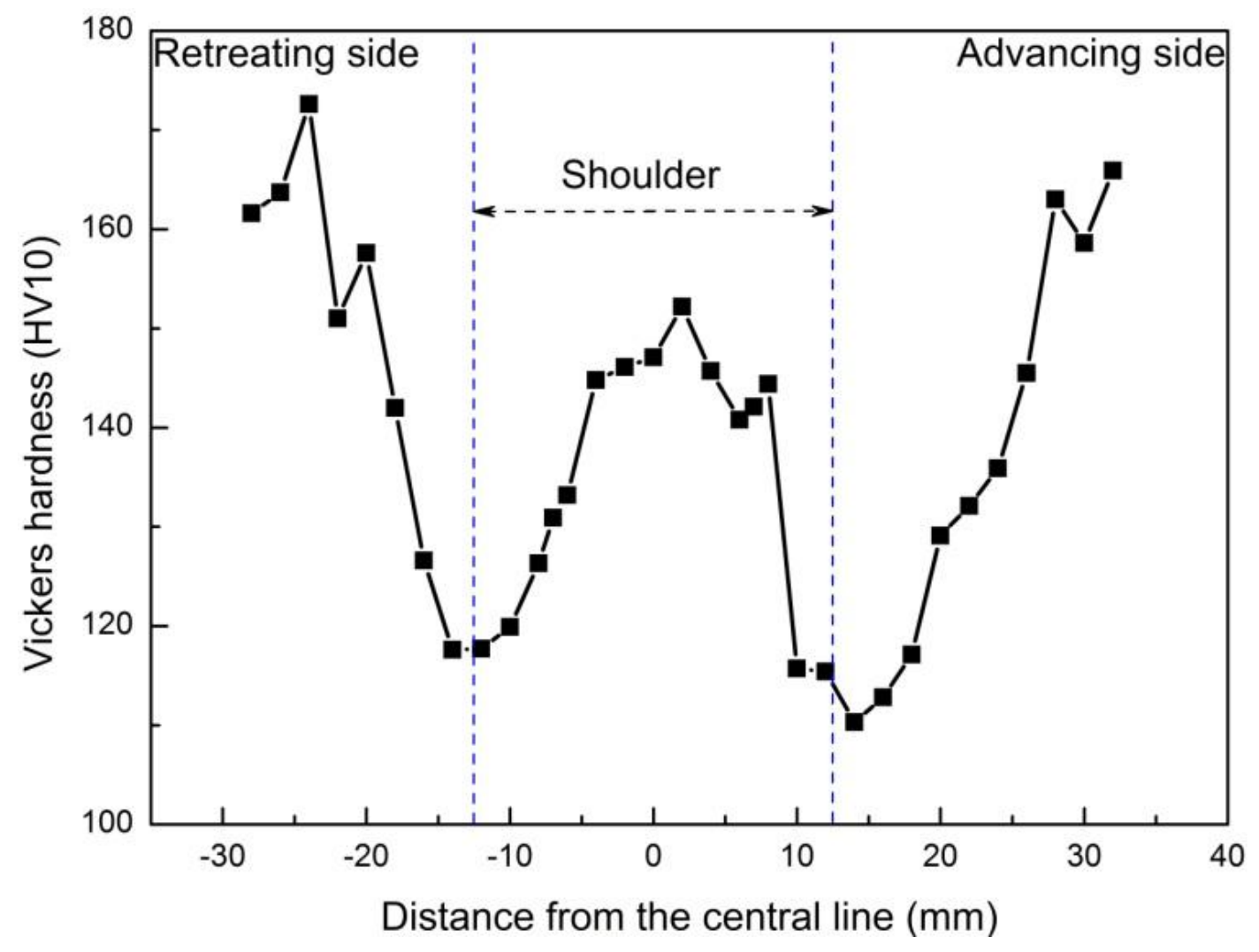

Fig. 5 Distribution of Vickers hardness across the FSW joint. 


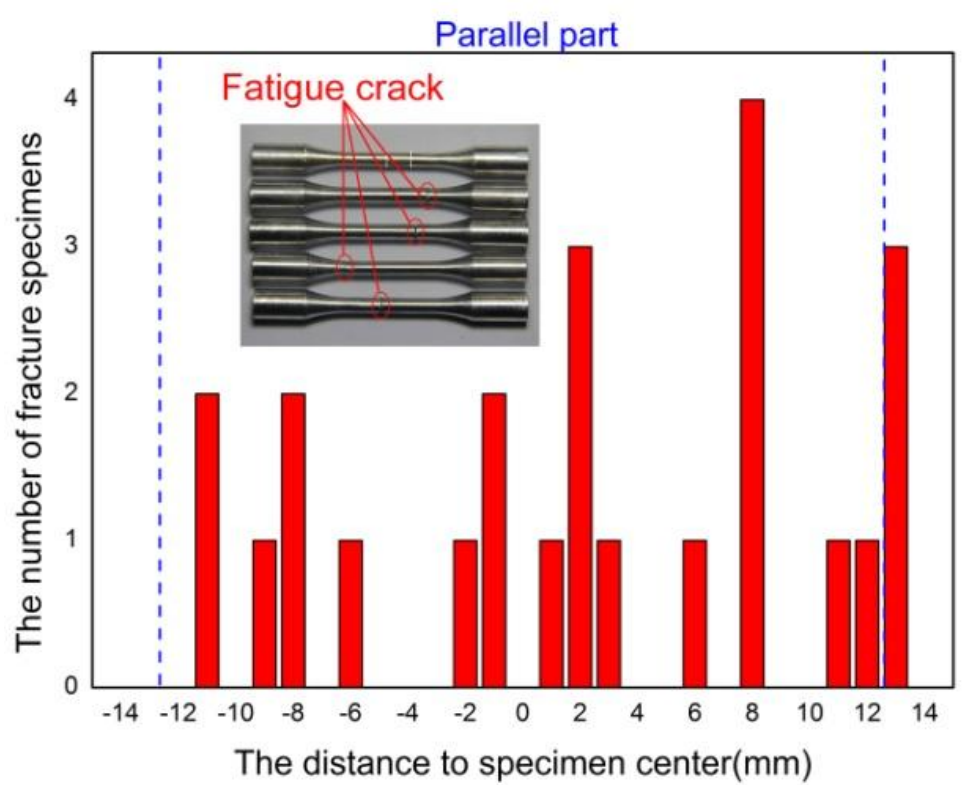

(a)

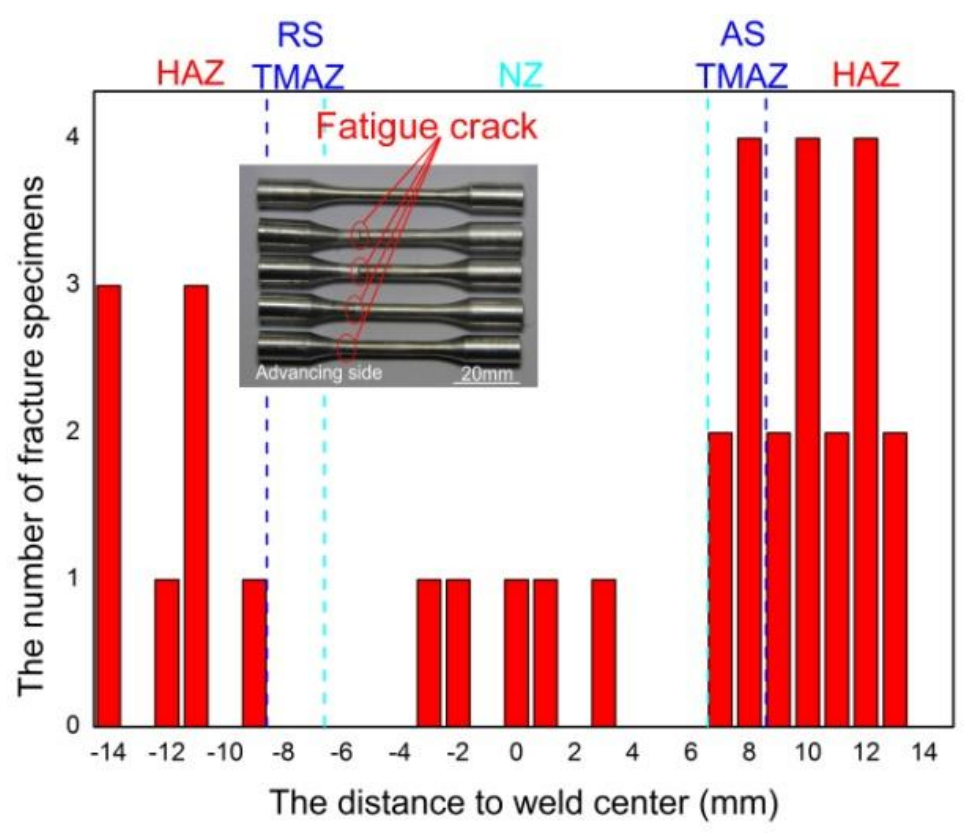

(b)

Fig. 6 Fracture position of the specimens (a) base metal; (b) FSW joint. 

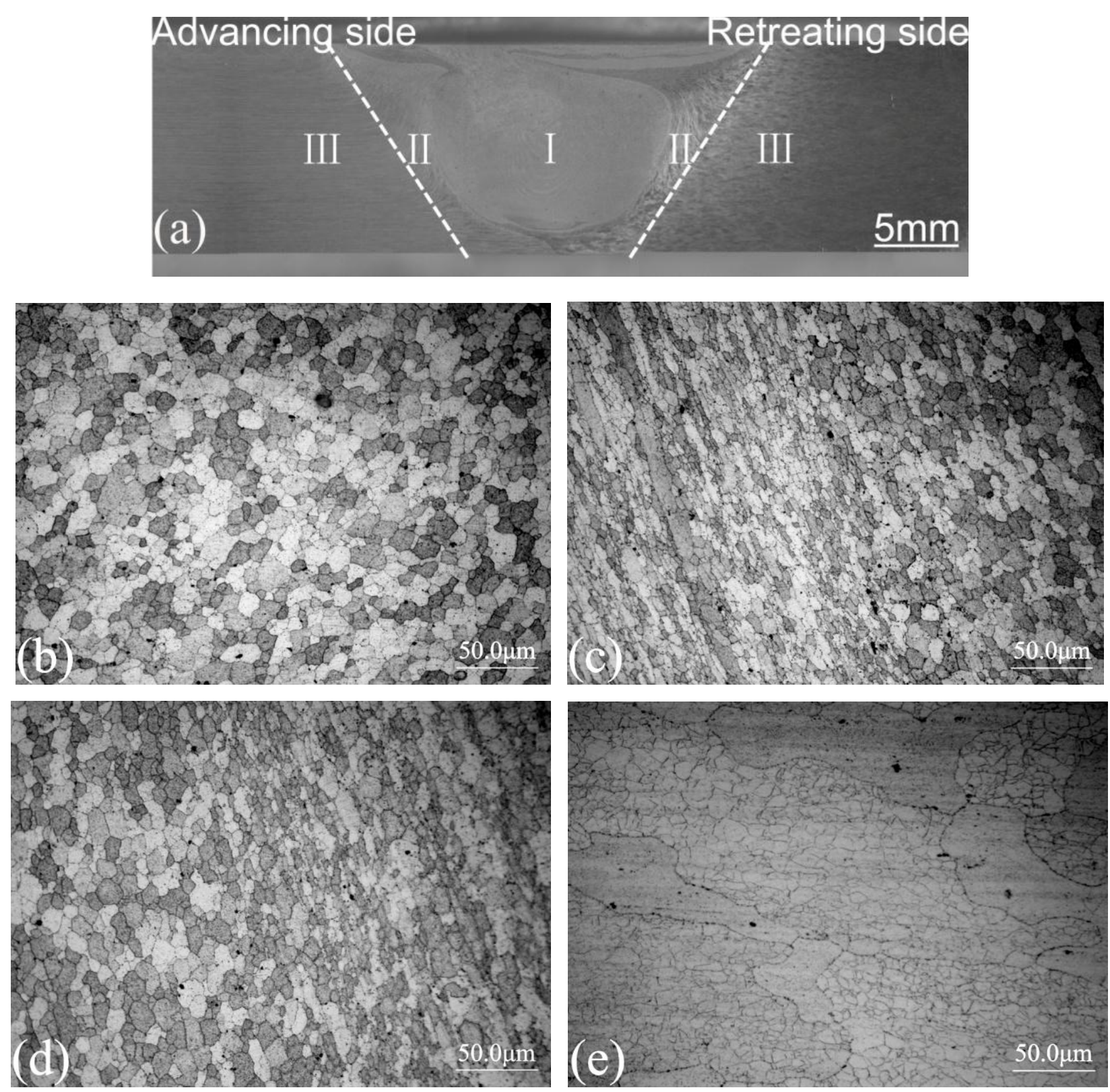

Fig. 7 Cross-section of the FSW joint for 7075-T7451 alloy (I: stir zone; II: TMAZ; III: HAZ) (a); microstructures of FSW joint for the stir zone (b); TMAZ at advancing side (c); TMAZ at retreating side (d); HAZ (e). 

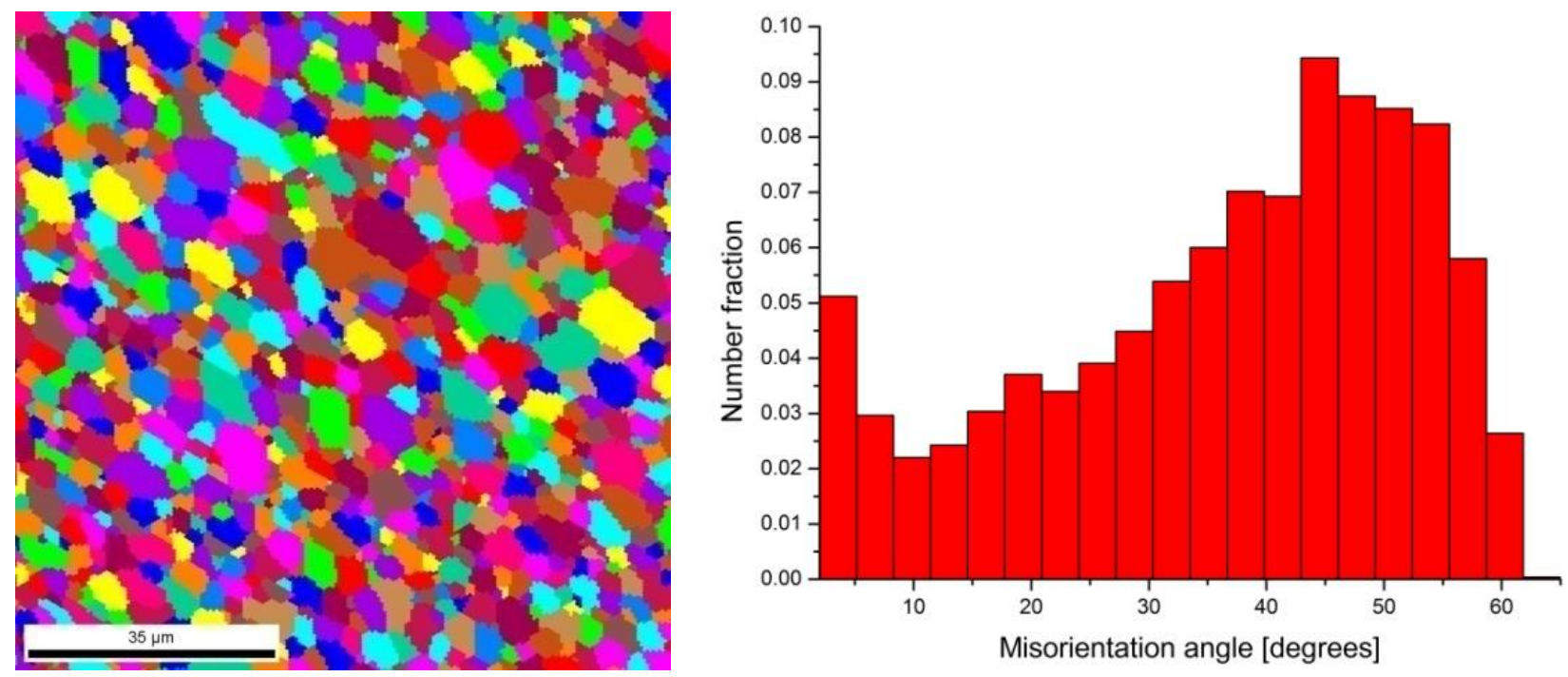

(a)
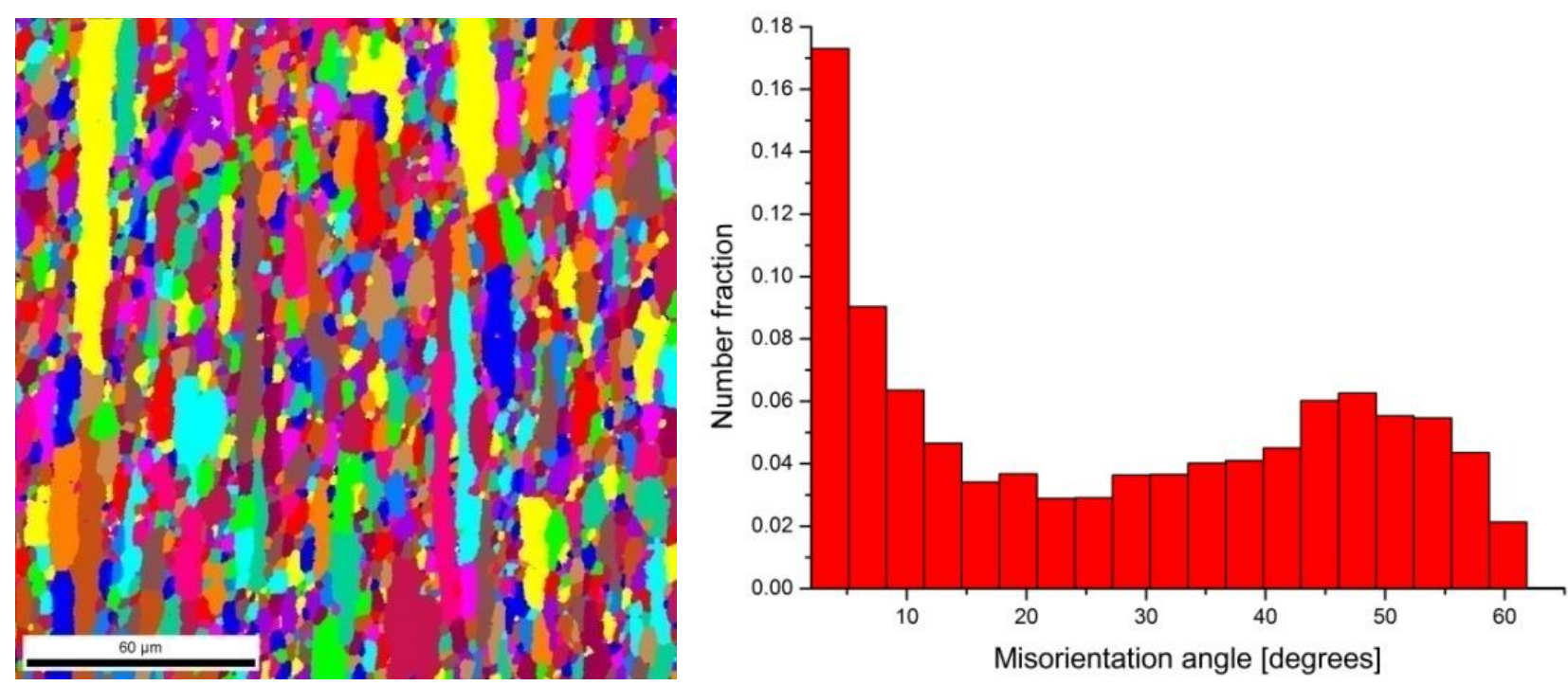

(b)
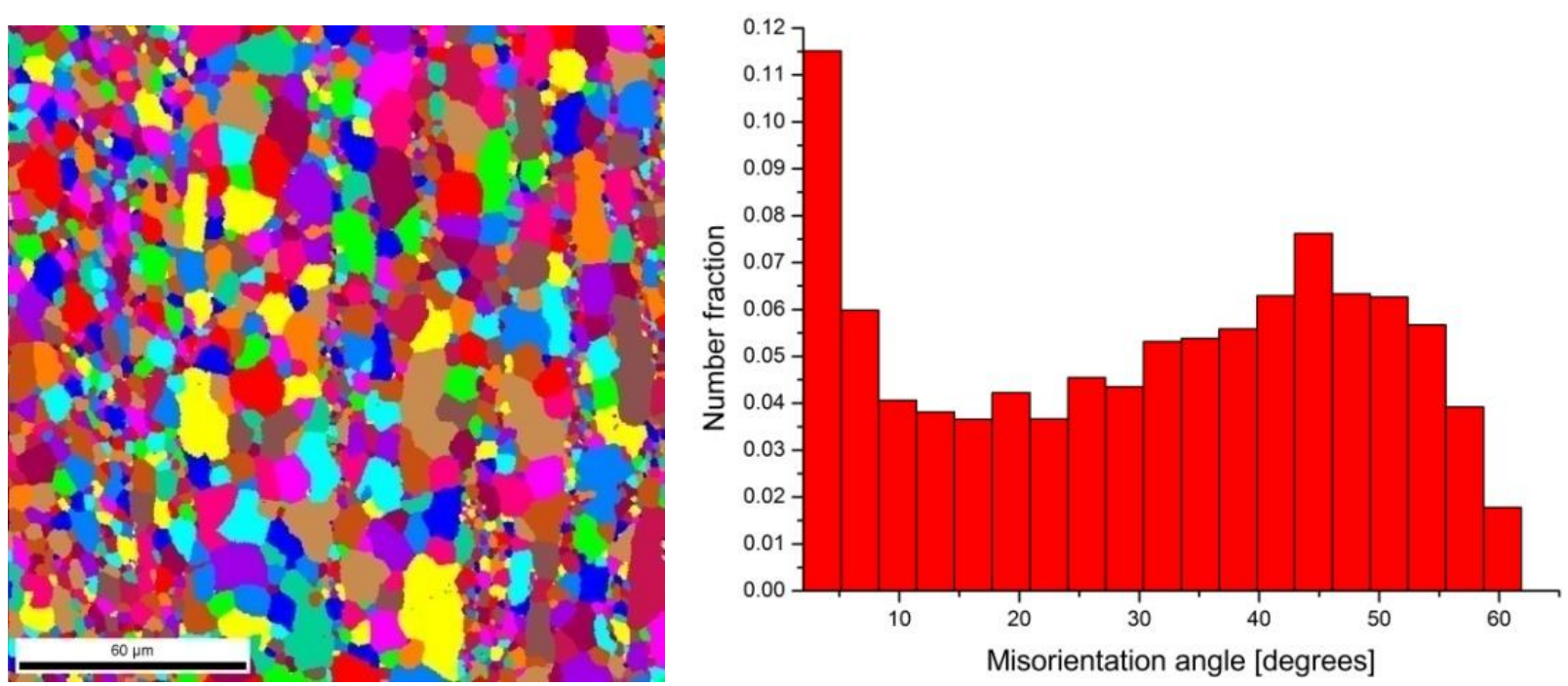

(c) 

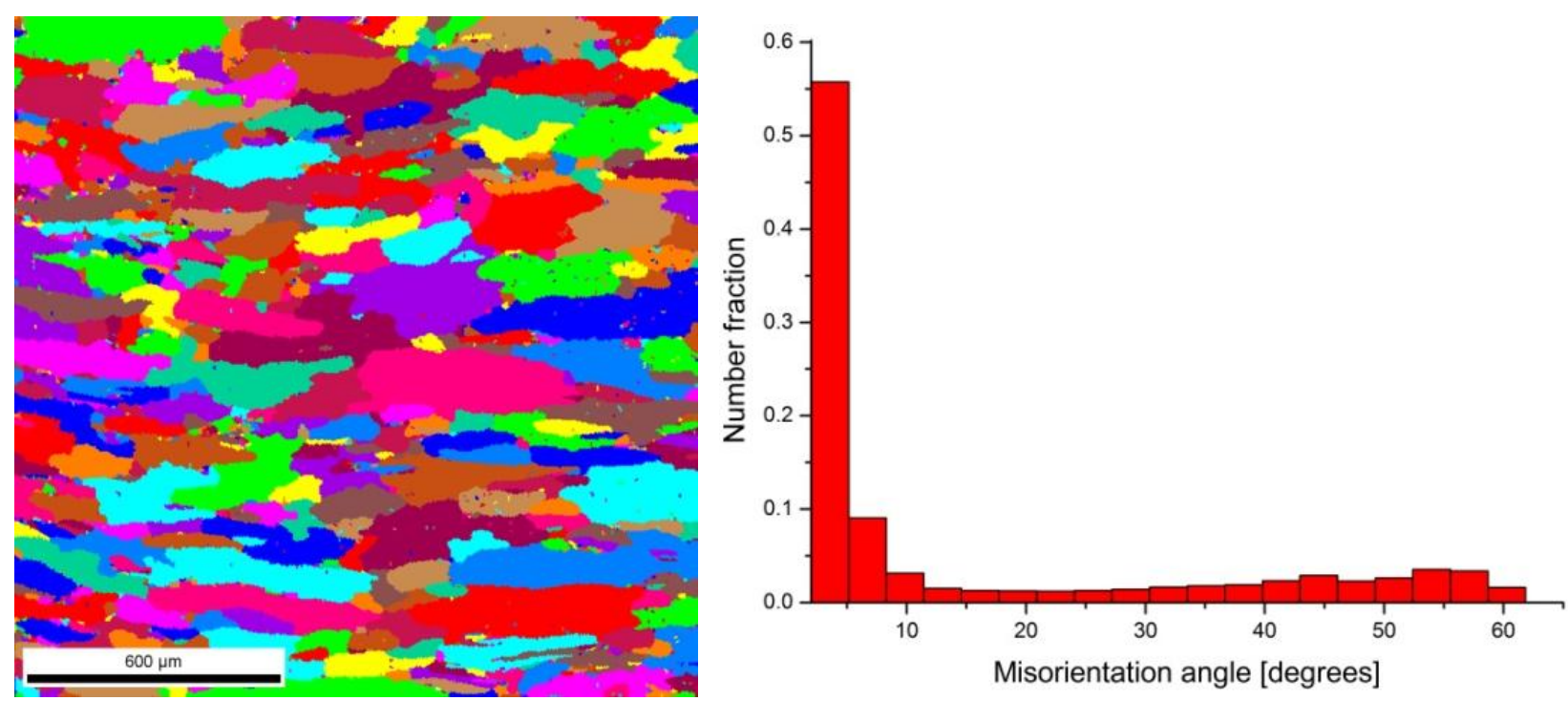

(d)

Fig. 8 Grain and misorientation angle distribution of the FSW joint for the stir zone (a); TMAZ at advancing side (b); TMAZ at retreating side (c); HAZ (d). 


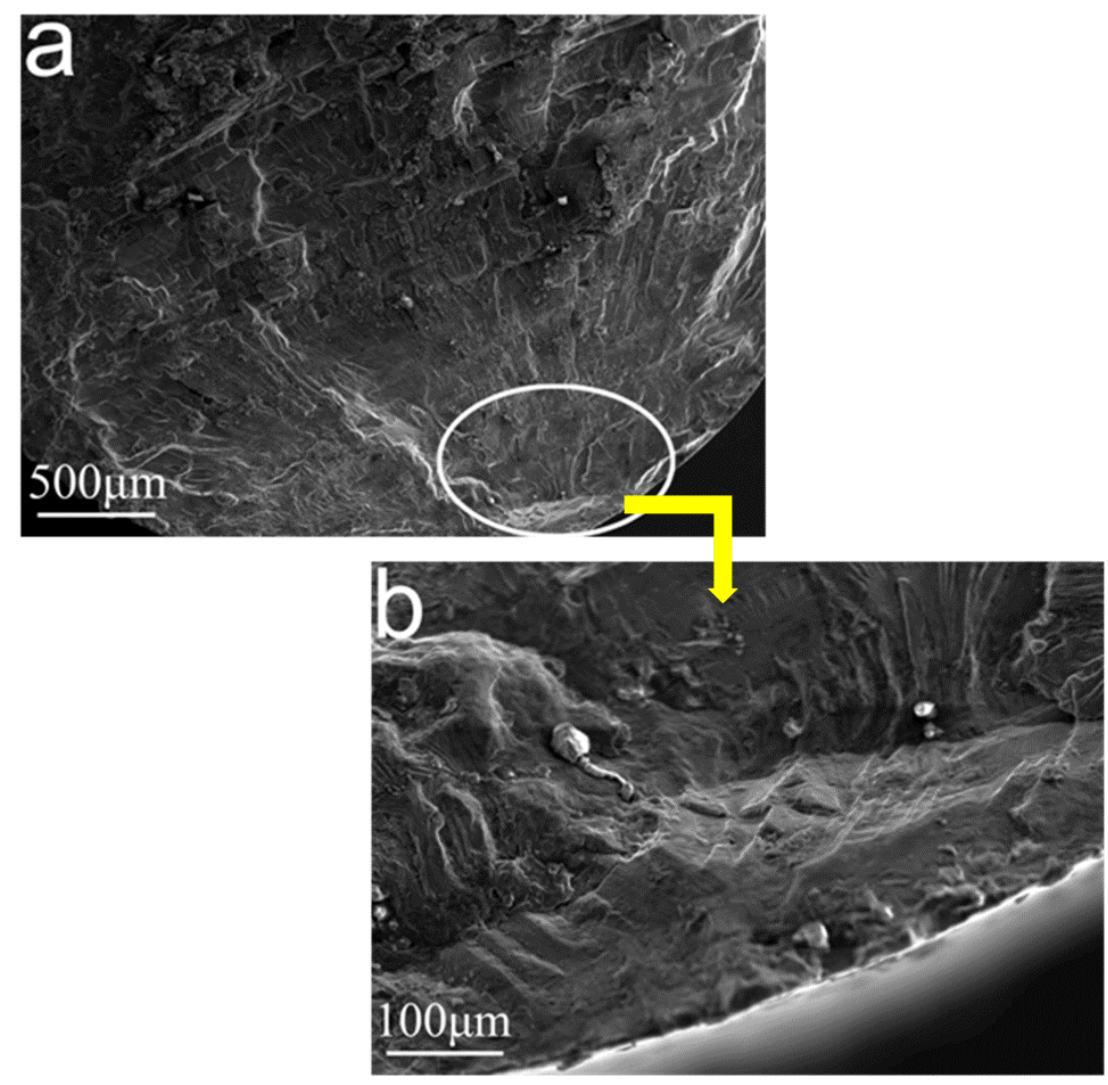

Fig. 9 Fractographic observation of the base metal: (a) low magnification; (b) high magnification at the crack source. 

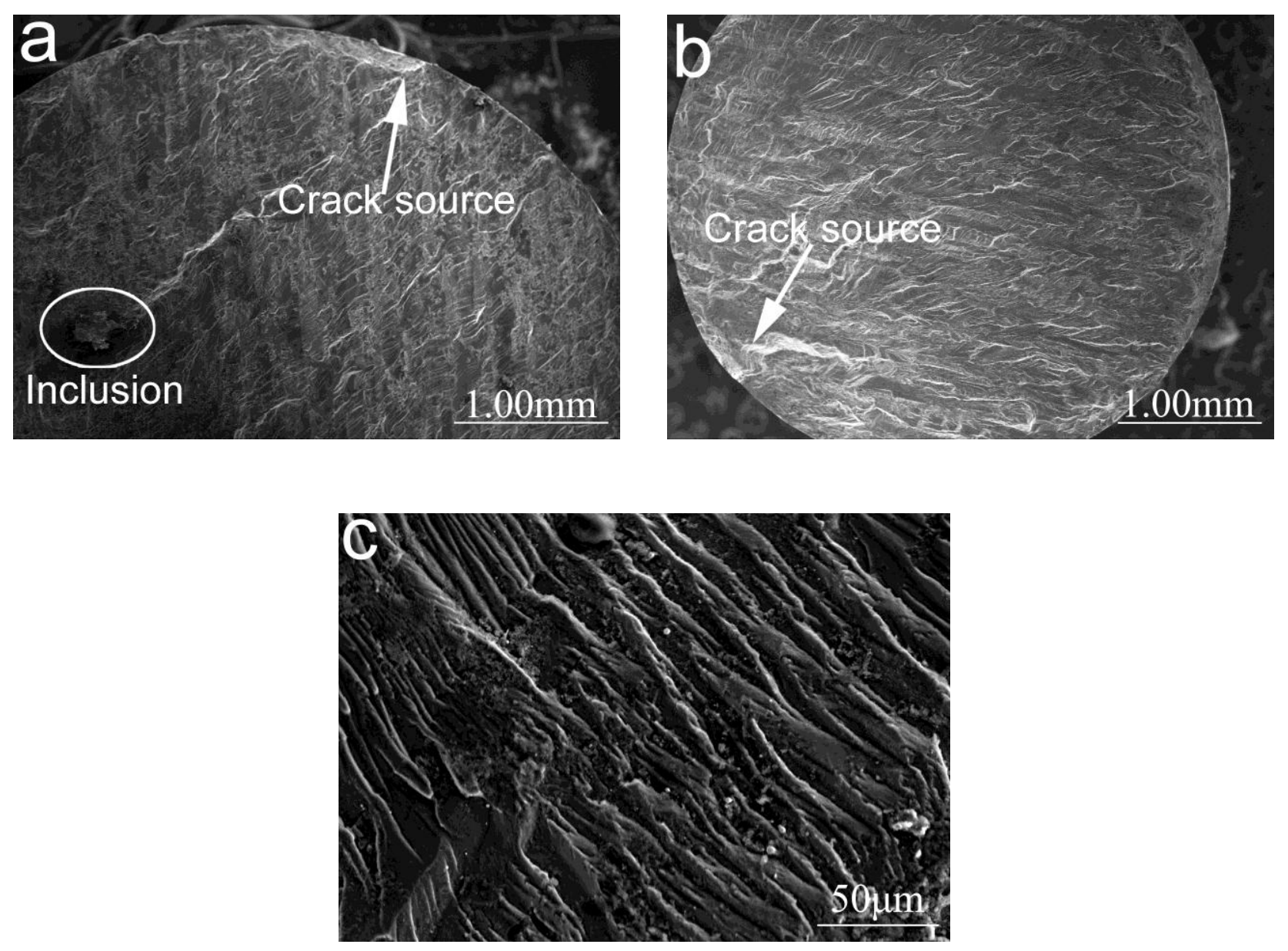

Fig. 10 Fractographic observation of the FSW welded joints. 


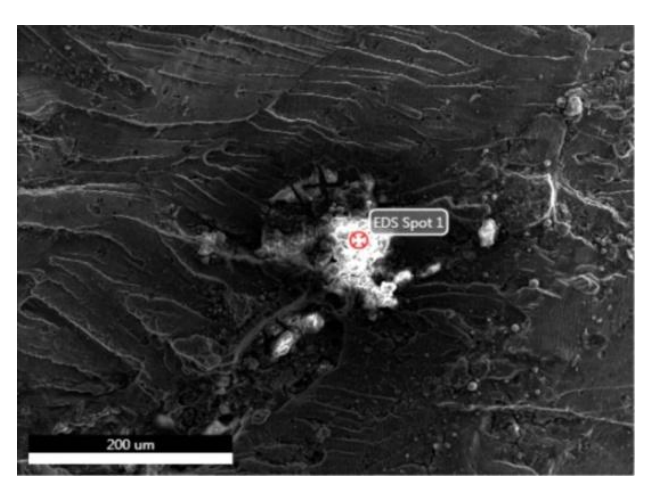

\begin{tabular}{|c|c|c|}
\hline Element & Weight \% & Atomic \% \\
\hline $\mathrm{C} \mathrm{K}$ & 20.54 & 30.87 \\
\hline $\mathrm{O} \mathrm{K}$ & 43.92 & 49.56 \\
\hline $\mathrm{NaK}$ & 0.71 & 0.56 \\
\hline $\mathrm{MgK}$ & 0.70 & 0.52 \\
\hline $\mathrm{AlK}$ & 22.14 & 14.82 \\
\hline $\mathrm{MoL}$ & 1.44 & 0.27 \\
\hline $\mathrm{FeK}$ & 10.55 & 3.41 \\
\hline
\end{tabular}

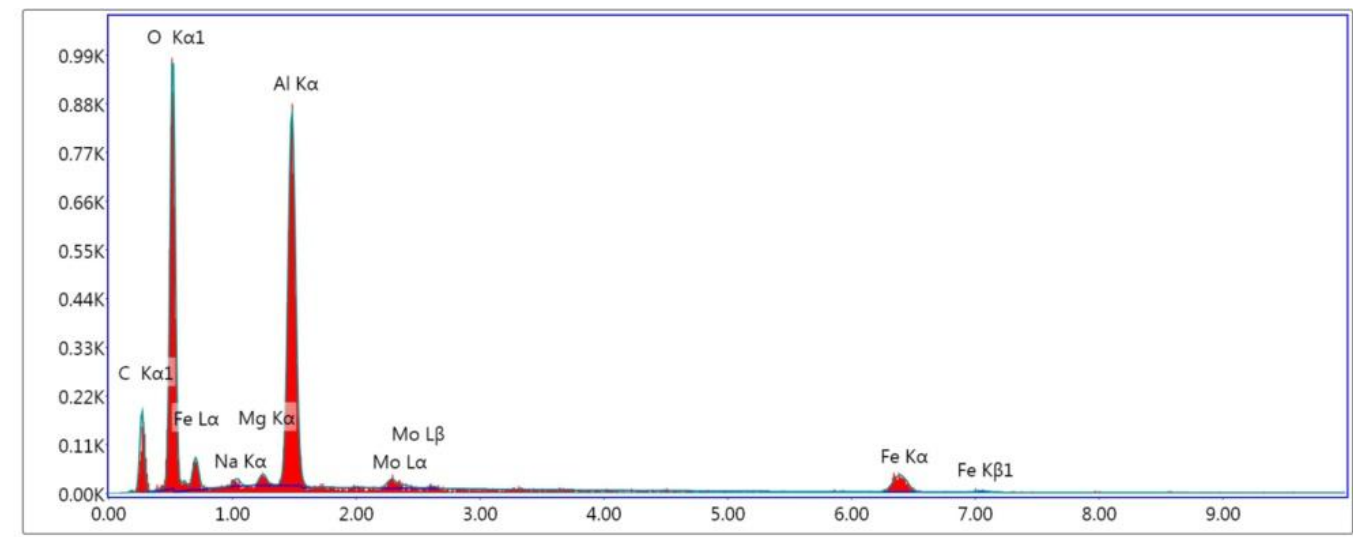

Lsec: 19.80 Cnts 0.000 keV Det: Octane Prime Det

(a)

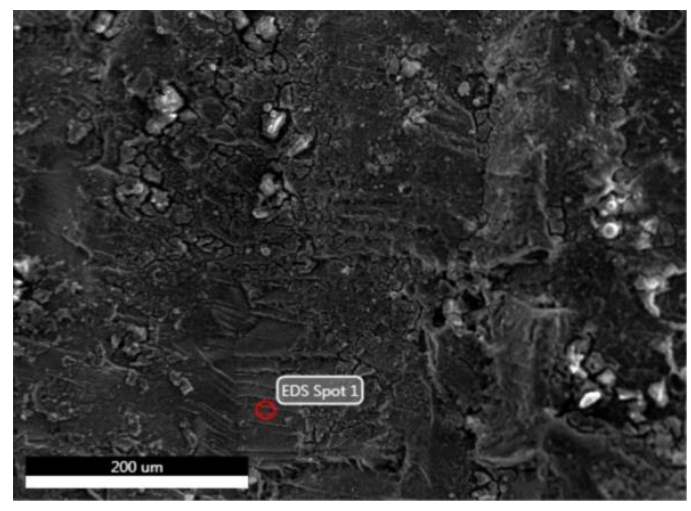

\begin{tabular}{|c|c|c|}
\hline Element & Weight \% & Atomic \% \\
\hline $\mathrm{O} \mathrm{K}$ & 6.02 & 10.08 \\
\hline $\mathrm{MgK}$ & 2.53 & 2.79 \\
\hline $\mathrm{AlK}$ & 84.96 & 84.46 \\
\hline $\mathrm{ZnK}$ & 6.49 & 2.66 \\
\hline
\end{tabular}

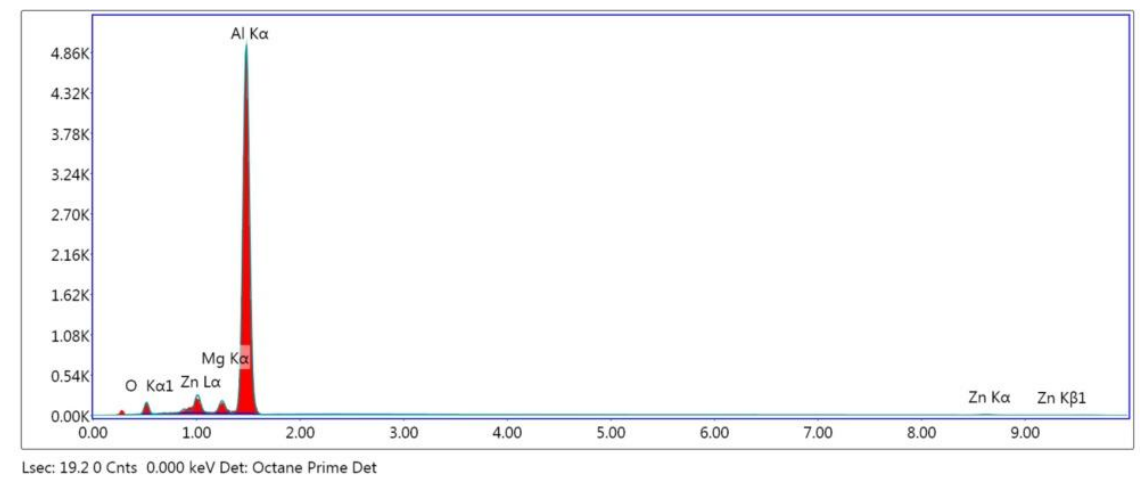

(b)

Fig. 11 EDS analysis for the inclusion (a); the FSW joint substrate (b). 